\title{
INFLUENCE OF FLUORIDE RELEASING LIGHT CURED RESIN COAT ON ENAMEL MINERALIZATION AND SURVIVAL OF METALLIC BRACKETS IN ORTHODONTIC PATIENTS: A 12-MONTHS RANDOMIZED CLINICAL TRIAL
}

\author{
Yasser Lotfy Abdelnaby* and Essam Abdelalim Nassar**
}

\begin{abstract}
Aim: To evaluate the effect of a fluoride releasing light cured resin coat on the mineralization and survival rate of orthodontic brackets.

Methods: Metal brackets $(n=360)$ were bonded to the teeth mesial to the first molars in 20 patients. A split-mouth design was used to randomly allocate diagonally opposite quadrants and Ortho-Choice Ortho-Coat was applied to half of the teeth after bonding. The bracket bond survival rate was assessed afterwards for a period of 12 months. Enamel mineralization was evaluated using Laser fluorescence (DIAGNOdent).
\end{abstract}

Results: Ortho-Coat significantly reduced enamel demineralization. No significant difference was found in bracket bond survival rates, with and without application of Ortho-Coat. The highest survival rates were recorded on incisors ( $96.2 \%$ with coat and $94.6 \%$ without a coat). The lowest survival rates were recorded on premolars ( $91.7 \%$ with coat and $88.3 \%$ without a coat).

Clinical Significance: Ortho-Coat effectively prevents enamel demineralization around orthodontic brackets over a 12-month period, but it has no pronounced effects on enhancing the bracket bond survival rate.

KEY WORDS: Enamel decalcification; Bracket survival rate; Fluoride coat

\section{INTRODUCTION}

Bonding orthodontic brackets to tooth enamel is considered one of the most common procedures in orthodontic practice. Enamel etching and the application of a primer and resin, are the main steps for the typical bonding protocol ${ }^{[1,2]}$. Success of such a technique depends on the bond strength between enamel and bracket. The bond strength is potentially affected by many factors including; etchant type and time, adhesive composition, mode of curing, bracket type, and base design ${ }^{[3-5]}$. Several primers and adhesives of different composition

* Professor of Orthodontic Department, Faculty of Dentistry, Mansoura University, Egypt

** Associate professor of Orthodontics, Preventive Dental Science Department, Imam Abdurahman Bin Faisal University, KSA and Orthodontic Department, Faculty of Dentistry, Mansoura University, Egypt. 
and curing modes have been developed with the purpose of enhancing the bond strength and reducing the failure rates of the brackets ${ }^{[6-8]}$. The adhesive type itself can influence the rate of failure.

No statistically significant differences in failure rates between chemically cured composite and light cured composites have been shown ${ }^{[9,10]}$. On the other hand, chemical cure glass ionomer cement has showed higher failure rates, as compared to chemically cured composite ${ }^{[11]}$. However, Millett et al. ${ }^{[12]}$ found no significant difference in failure rates between chemical cured composites and compomers, which had shown better enamel protection against decalcification.

Fixed orthodontic appliances could lead to enamel demineralization and the formation of white spot lesions (WSLs) ${ }^{[13]}$. The appearance of WSLs negatively affects the satisfaction of orthodontists and patients about the treatment results, despite its excellence. Fixed orthodontic appliances promote food accumulations, and hence encourage dental plaque development. Subsequently, the acidogenic bacteria numbers can noticeably increase and will tackle fermentable carbohydrates producing acid by-products, and decrease the plaque $\mathrm{pH}$, whereby enamel demineralization may then occur ${ }^{[14]}$.

Many attempts have been tried to inhibit WSLs appearance. These methods include; patient motivation, oral hygiene measures, along with the utilization of fluoride derivatives ${ }^{[15,16]}$. Fluoride application could be performed via professional and non-professional modalities. The later includes the use of fluoride rinses or gels. Professional methods include the application of fluoride varnishes, fluoride releasing adhesives and elastomeric as well as fluoride sealants or coats ${ }^{[17-19]}$.

A fluoride-releasing light-cured resin coat which is now available in markets, can act as a mechanical block between plaque and the enamel surface, surrounding the orthodontic brackets. Fluoride coat application has been shown to significantly decrease the microleakage under the brackets, and to enhance the bond strength ${ }^{[20]}$.
The current study was performed to assess the effect of applying fluoride-releasing light-cured resin coat on enamel mineralization, and the survival rate of the metal orthodontic brackets bond.

\section{MATERIALS AND METHODS}

This was a single-center, alternated split-mouth, two-arm randomized clinical trial with 1:1 allocation ratio.

\section{Assessment of eligibility}

The study was conducted on 20 patients (10 females and 10 males) with a mean age of 15.2 years, seeking orthodontic treatment at Orthodontic Department, faculty of Dentistry, Mansoura University. Inclusion criteria included: a complete permanent dentition with fully erupted teeth, no gross crown anomalies, no restoration on the labial or buccal surface that might alter bracket bonding, and no gingival hyperplasia. Exclusion criteria were hypoplastic enamel, orofacial syndrome, cleft lip and palate deformities are. All patients were informed about the study and agreed to participate.

\section{Sample size calculation}

Sample size was assessed by $\mathrm{G}^{*}$ Power software (version 3.0.10). Assuming type I statistical error of 5\% and the 2-tailed statistical test, this study was designed to have a power of $95 \%$ based on the previous study by Demito et al. ${ }^{[21]}$ whereby the role of fluoride varnish in the inhibition of white spot lesions development was studied. The mean levels of decalcification were $1.090 .89 \pm$ and $1.401 .48 \pm$ in the varnish (test) and non-varnish (control) groups respectively. Therefore, the calculated sample size was 20 patients per trial arms.

All patients were provided with standardized oral hygiene instructions at base line. Prophy was done for all patients at the baseline, before placing brackets and bonding. Patients were instructed to use their regular toothbrush and tooth paste, as their routine oral hygiene practice. Twice daily tooth brushing was emphasized. Oral hygiene instructions were reemphasized on every recall/follow up visit. 
Metal brackets $(n=360)$ Roth prescription and 0.022-inch slot (Ormoco, USA) were bonded to teeth, mesial to the first molars. The bonding procedures were done according to the manufacturer's instructions. Isolation was obtained by cheek retractors, cotton rolls, saliva ejectors and high suction. The enamel surface was etched for 30 seconds by $37 \%$ phosphoric acid. Teeth were washed thoroughly with water and dried with air. A thin coat of Transbond XT primer (3M, Unitek, Calif, USA) was placed to the etched dry enamel and to the underside of the bracket. Transbond XT adhesive resin (3M, USA) was applied to the bracket base. Each bracket was placed in its correct position on the tooth surface and pressed firmly under a 300gm compressive force applied with a force gauge (Correx Co, Bern, Switzerland). The excess bonding resin was removed using a sharp scaler and the adhesive was light cured for 40 seconds (20 seconds on the incisal and gingival aspect of each bracket).

\section{Enrollment}

After bonding, all the subjects were randomly allocated to two groups and a split-mouth design was applied. The oral cavity was divided into 2 units of alternative quadrants (maxillary right quadrant and mandibular left quadrant as $1^{\text {st }}$ unit and the remaining quadrants as the $2^{\text {nd }}$ unit). These quadrants were considered the units of randomization, where the $1^{\text {st }}$ unit was assigned to a group and the other was automatically assigned to the other group. Patients fitting the inclusion criteria were serially numbered from 01 to 20 and randomly assigned to receive the test intervention in the $1^{\text {st }}$ unit using the Random Allocation Software (http:// mahmoodsaghaei.tripod.com/Softwares/randalloc. html\# Random Allocation Software). The fluoridereleasing, light-cured resin coat (Ortho-Choice Ortho-Coat, Pulpdent, Watertown, Mass, USA) was applied to the labial and buccal enamel surfaces around the brackets. All the bonding procedures were done by a single operator.

\section{Allocation}

The allocation sequence was concealed with sequentially numbered, opaque, sealed and stapled envelopes that kept with an assistant who was not involved in treatment and measuring the outcome. The patient was not aware which side received the fluoride coat, but it was impossible to blind the operator because of the bonding technique. The first arch wire 0.014-inch Ni Ti was inserted 24 hours after bracket bonding and followed by various round and rectangular $\mathrm{Ni}-\mathrm{Ti}$ and stainless-steel wires according to the treatment progress. Instructions for oral hygiene care and appliance maintenance were given to all patients. A participant flow chart and intervention allocation is presented in fig.l.

\section{Outcome measures}

Bond failure was recorded during the monthly orthodontic visits for 12 months. Any tooth which exhibited a bond failure was rebounded and excluded in the bonding failure and mineralization assessments. The level of enamel surface mineralization around the brackets was evaluated just after bonding, and after 12 months using Laser fluorescence device (Kavo DIAGNOdent pen, Kavo, Germany). Initially, the DIAGNOdent was calibrated alongside its own ceramic standard to guarantee a precise evaluation. Measurements were done on the labial and buccal surfaces, $1 \mathrm{~mm}$ away and opposite the center of the mesial, distal, gingival and incisal or occlusal edges of the brackets and the maximum reading was recorded. All readings were assessed thrice by another operator who was not aware about the treatment allocation and the mean of all the three readings was estimated. For each patient, the scores of all the teeth mesial to the maxillary and mandibular first molars were added and the mean was considered for statistical analysis.

\section{Statistical analysis}

The collected data was statistically analyzed. The survival rates of brackets were evaluated using log-rank tests. The significant difference in enamel mineralization was evaluated, using the t-test. Significance for all statistical tests was predetermined at $P<0.05$. 


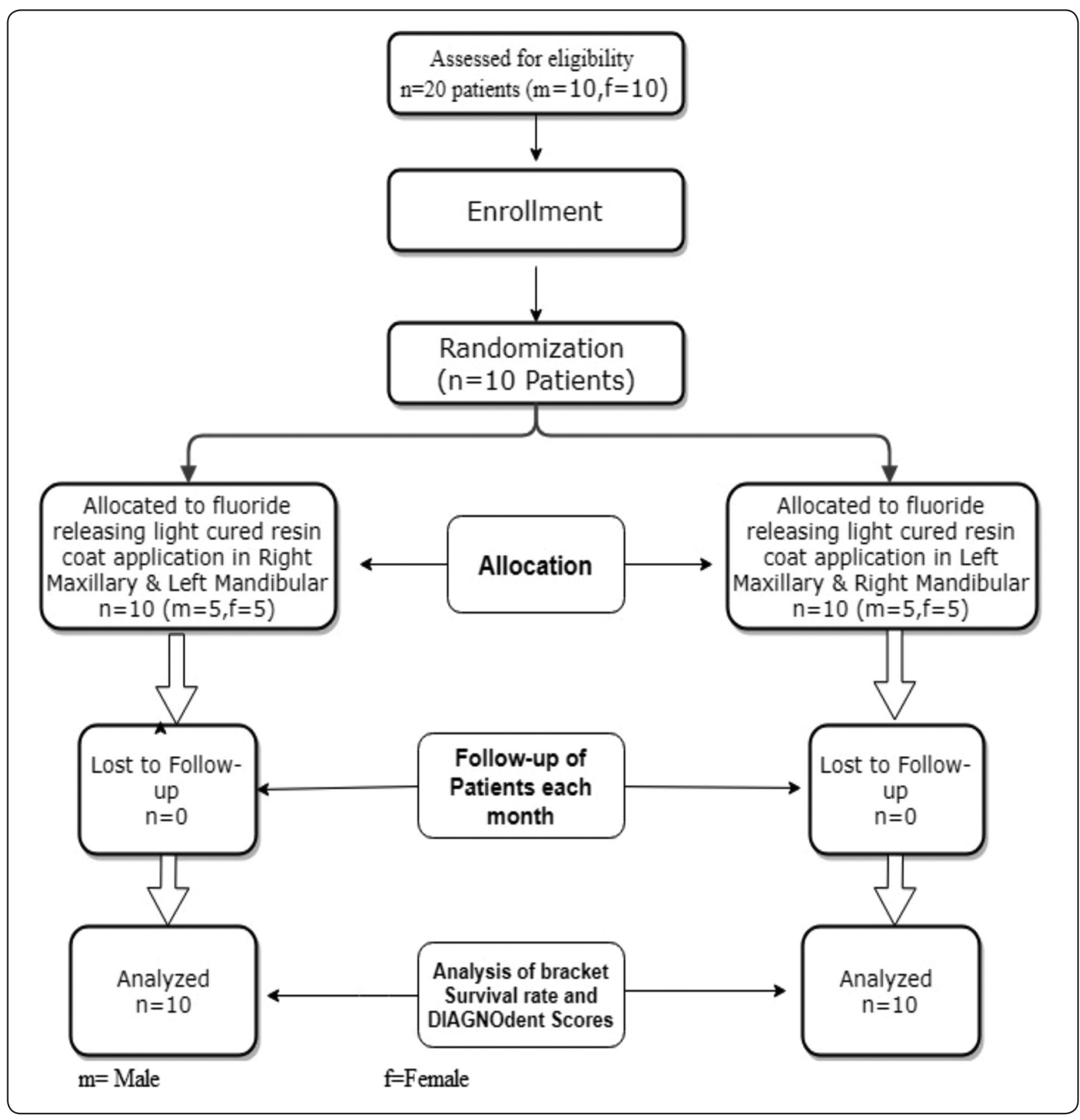

Fig. (1) Flow chart of the experimental design.

\section{RESULTS}

Neither overgrowth of the gingiva nor gingival inflammation was noticed over the observation period of 12 months.

The mean pretreatment DIAGNOdent values were $6.361 .53 \pm$ without fluoride coat and 5.93 \pm
1.46 with a coat. There was no significant difference $(P>.05)$ between the two groups as described in Table 1. On the other hand, there was a significant difference $(P<.05)$ in the mean post-treatment DIAGNOdent scores without the application of the fluoride coat $(3.84 \pm 1.11)$ and those with the coat application (2.20 \pm 0.8$)$ as seen in Table I and fig. 2 . 
Bracket bond survival numbers and rates for incisors, canines, and premolars with and without fluoride resin coat application, as well as the results of the log-rank test are presented in Table II and Table III. The highest survival rates were recorded on incisors (96.2\% with coat and $94.6 \%$ without a coat). On the other hand, the lowest survival rates were recorded on premolars $(91.7 \%$ with coat and $88.3 \%$ without coat). No significant differences were found in bracket bond survival rates between incisors, canines, and premolars in either group, with and without fluoride coat application, $(P>0.05)$. No significant differences were found in the two groups on different tooth types $(P>0.05)$ regarding the effect of treatment time or duration (3,6,9 and 12 months) of the bracket survival rate, except on canines in both groups and on premolars in the group without the application of fluoride coat $(P<0.05)$.

TABLE (I) Mean and standard deviations (SD) for pretreatment and post-treatment changes of DIAGNOdent measurements of the two studied groups and the results of the t-test.

\begin{tabular}{ccccc}
\hline $\begin{array}{c}\text { DIAGNO dent } \\
\text { Scores }\end{array}$ & $\begin{array}{c}\text { Without fluoride coat } \\
\text { Mean } \pm \text { SD }\end{array}$ & $\begin{array}{c}\text { With fluoride coat } \\
\text { Mean } \pm \text { SD }\end{array}$ & t & $P$ \\
\hline Pretreatment & $6.36 \pm 1.53$ & $5.93 \pm 1.46$ & 2.704 & 0.493 \\
Post-treatment (after 12 months) & $3.84 \pm 1.11$ & $2.20 \pm .80$ & 15.93 & $.000^{*}$ \\
\hline
\end{tabular}

$P<0.05$ was considered to be significant

TABLE (II) Bracket bond survival rates of incisors, canines and premolars with and without fluoride resin coat application and the results of log-rank test.

\begin{tabular}{|c|c|c|c|c|c|c|c|c|}
\hline \multirow[t]{2}{*}{ Date } & \multicolumn{2}{|c|}{ Incisors } & \multicolumn{2}{|c|}{ Canines } & \multicolumn{2}{|c|}{ Premolars } & \multicolumn{2}{|c|}{ All teeth } \\
\hline & $\begin{array}{c}\text { With } \\
\text { Fluoride } \\
\text { Coat }\end{array}$ & $\begin{array}{c}\text { Without } \\
\text { Fluoride } \\
\text { Coat }\end{array}$ & $\begin{array}{l}\text { With } \\
\text { Fluoride } \\
\text { Coat }\end{array}$ & $\begin{array}{c}\text { Without } \\
\text { Fluoride } \\
\text { Coat }\end{array}$ & $\begin{array}{l}\text { With } \\
\text { Fluoride } \\
\text { Coat }\end{array}$ & $\begin{array}{c}\text { Without } \\
\text { Fluoride } \\
\text { Coat }\end{array}$ & $\begin{array}{l}\text { With } \\
\text { Fluoride } \\
\text { Coat }\end{array}$ & $\begin{array}{c}\text { Without } \\
\text { Fluoride } \\
\text { Coat }\end{array}$ \\
\hline 3 months & $100 \%$ & $100 \%$ & $100 \%$ & $100 \%$ & $98.3 \%$ & $98.3 \%$ & $98.3 \%$ & $98.3 \%$ \\
\hline 6 months & $100 \%$ & $98.9 \%$ & $100 \%$ & $96.4 \%$ & $96.7 \%$ & $95 \%$ & $96.7 \%$ & $95 \%$ \\
\hline 9 months & $97.5 \%$ & $96.7 \%$ & $97.5 \%$ & $92.4 \%$ & $95 \%$ & $91.7 \%$ & $95.6 \%$ & $94.1 \%$ \\
\hline 12 months & $96.2 \%$ & $94.6 \%$ & $95 \%$ & $89.3 \%$ & $91.7 \%$ & $88.3 \%$ & $94.4 \%$ & $93.3 \%$ \\
\hline $\begin{array}{l}\text { Log-rank within } \\
\text { group }\end{array}$ & 0.057 & 0.076 & 0.026 & 0.005 & 0.14 & 0.031 & 0.54 & 0.16 \\
\hline $\begin{array}{c}\text { Log-rank among } \\
\text { groups }\end{array}$ & \multicolumn{2}{|c|}{0.60} & \multicolumn{2}{|c|}{0.37} & \multicolumn{2}{|c|}{0.35} & \multicolumn{2}{|c|}{0.29} \\
\hline $\begin{array}{l}\text { Overall log- } \\
\text { rank }\end{array}$ & \multicolumn{4}{|c|}{ With Fluoride Coat: $P=0.49$} & \multicolumn{4}{|c|}{ Without Fluoride Coat: $P=0.34$} \\
\hline
\end{tabular}

$P<0.05$ was considered to be significant 
TABLE (III) Numbers of bracket failures bonded to different tooth types with and without fluoride coat application.

\begin{tabular}{|c|c|c|c|c|c|c|c|}
\hline \multirow[b]{2}{*}{ Tooth type } & \multicolumn{3}{|c|}{ With fluoride coat } & \multicolumn{3}{|c|}{ Without fluoride coat } & \multirow[b]{2}{*}{ Total } \\
\hline & $\begin{array}{l}\text { Bracket } \\
\text { Number }\end{array}$ & $\begin{array}{l}\text { Bracket } \\
\text { Failures }\end{array}$ & Failure $\%$ & $\begin{array}{l}\text { Bracket } \\
\text { Number }\end{array}$ & $\begin{array}{l}\text { Bracket } \\
\text { Failures }\end{array}$ & Failure $\%$ & \\
\hline Incisors & 80 & 3 & $3.75 \%$ & 80 & 5 & $6.25 \%$ & $5 \%$ \\
\hline Canines & 40 & 2 & $5 \%$ & 40 & 3 & $7.5 \%$ & $3.3 \%$ \\
\hline Premolars & 60 & 5 & $8.3 \%$ & 60 & 7 & $11.7 \%$ & $10 \%$ \\
\hline All teeth & 180 & 10 & $5.5 \%$ & 180 & 15 & $8.3 \%$ & $6.9 \%$ \\
\hline
\end{tabular}

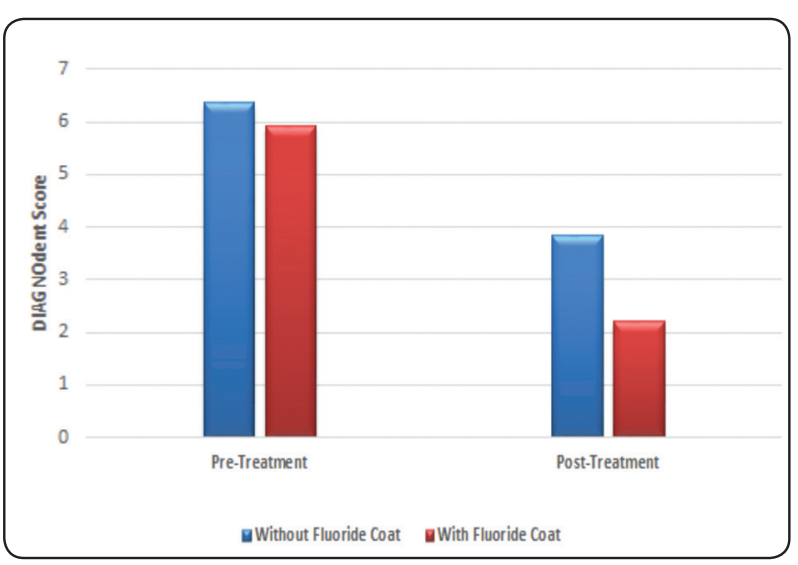

Fig. (1) Flow chart of the experimental design.

\section{DISCUSSION}

The existing study was performed to assess the influence of fluoride resin coat application on the enamel decalcification and bracket bond survival rate. Survival analysis is an accurate approach to estimate the cumulative probability of bracket failure at various times during the study. A randomly alternated split-mouth design was used in this study for reasons of standardization and to avoid any bias in the results. Enamel demineralization was quantified by a DIAGNOdent generated a laser light with $655 \mathrm{~nm}$ wavelength. The tip of the device measures the reflected laser fluorescence from tooth surface indicating the degree of demineralization. Higher readings indicating greater demineralization. The DIAGNOdent pen is considered currently the most accurate device for detecting enamel demineralization and it widely used in both in vivo and invitro studied ${ }^{[22]}$. The device is easy to use but its readings might be affected by stains, calculus, plaque and bacterial metabolites ${ }^{[23,24]}$. Therefore, a regular checkup and oral hygiene instructions were reassured on every recall/follow up visit.

The results of this study showed a significant difference between DIAGNOdent values around bonded brackets coated with fluoride releasing coat and those without fluoride coat after a 12-month treatment period $(P \leq 0.05)$. This indicated higher enamel mineralization content following the application of the fluoride resin coat compared to the teeth bonded without a coat. Fluoride has always remained the gold standard in remineralization mechanism in the oral cavity. Besides the basic flouro-apatite formation that resists decalcification, the fluoride-releasing light-cured resin coat also acts as a mechanical barrier between oral fluids, plaque and the enamel surface surrounding orthodontic brackets, thereby preventing enamel demineralization ${ }^{[20]}$. Nalbantgil et al. ${ }^{[25]}$ found that one application of fluoride varnish can decrease enamel lesion depth adjacent to bonded brackets by about $40 \%$ for 3 months, whereas Mehta et al. ${ }^{[26]}$ concluded that Clipro XT, which is a light cure fluoride release varnish, can prevent $90-100 \%$ of demineralization for up to 3 months. However, both studies have suggested the multiple applications of 
fluoride release varnishes to control demineralization over the whole treatment period, while single application fluoride resin coat was efficient in our study in preventing the decalcification over a 12-month period.

Regarding the brackets bond survival rate, the overall survival rate was $94.4 \%$ for brackets bonded and coated with fluoride coat light cured resin, while it was $93.3 \%$ for bonded bracket without coat application. These values are considered to be within the clinical acceptable range ${ }^{[27]}$. The highest survival rates were recorded on incisors (96.2\% and 94.6\%). While the lowest survival rates $91.7 \%$ and $88.3 \%$ were recorded on premolars $(91.7 \%$ and $88.3 \%$ ). However, there were no significant differences found in bracket bond survival rates between incisors, canines, and premolars in either group. These findings are in disagreement with other studies which have reported a significant difference between survival rates for canine and premolar teeth, as compared to incisors ${ }^{[28]}$. They attributed this high failure rate of the posterior teeth to poor moisture control, partial eruption of the second premolars and heavier occlusal forces being exerted in the posterior area [29-31]. These controversies could be attributed to the differences in bonding systems or study periods.

Although the fluoride coat was cured in a separate step after adhesive light curing, the aim being to increase the bond strength and to decrease the failure rates, as doubling the curing time would enhance polymerization and increase the energy density ${ }^{[20,32]}$. The results of the present study revealed no significant difference in the survival rate between teeth bonded with and without fluoride coat application. In addition, no significant difference between bracket survival rates was found between the different periods (3, 6, 9 and 12 months); except for the canines in both groups and the premolars in the group without the application of fluoride coat $(P<0.05)$. The latter could be explained by the differences in teeth position and angulation that could affect the amount of force applied. A significant effect of the malocclusion type on the failure rate has also been reported in a previous study ${ }^{[33]}$.

Light cure fluoride resin coat is effective in preventing enamel demineralization around orthodontic brackets over a 12-month period, but it has no pronounced effects in enhancing the bracket bond survival rate.

A further study evaluating the role of fluoride coat over a longer period is recommended.

\section{Limitation of this study:}

The overall DIAGNOdent mean score for each patient was calculated; however a mean DIAGNOdent score for each individual tooth would be more durable clinically.

\section{Disclosure Statement:}

The authors declare no conflict of interest.

\section{ACKNOWLEDGEMENT}

We thank Prof. Maha ElTantawi, Professor of Dental Public Health and biostatistics, Imam Abdulrahman Bin Faisal University for her assistance in randomization of the sample.

\section{REFERENCES}

1. Bishara SE, Gordan VV, VonWald L, Olson ME. Effect of an acidic primer on shear bond strength of orthodontic brackets. Am J Orthod Dentofacial Orthop. 1998; 114:243-47.

2. Bishara SE, Oonsombat C, Soliman MMA, Warren JJ, Laffoon JF, Ajlouni R. Comparison of bonding time and shear bond strength between a conventional and a new integrated bonding system. Angle Orthod. 2005; 75:237-42.

3. Faltermeier A, Behr M, Müssig D. A comparative evaluation of bracket bonding with 1-,2-, and 3-component adhesive systems. American Journal of Orthodontics and Dentofacial Orthopedics. 2007;132:144-e1.

4. Urabe H, Rossouw PE, Titley KC, Yamin C. Combination of etchants, composite resins, and bracket systems: An 
important choice of orthodontic bonding procedures. Angle Orthod. 1999; 69:267-75.

5. Talpur M, Cunningham SJ, Moles DR, and Steven P. Jones SP. The relationship between base dimensions, force to failure, and shear bond strengths of bondable molar tubes. Angle Orthod. 2012; 82: 536-40.

6. Davari AR, Yassaei S, Daneshkazemi AR, Yosefi MH. Effect of different types of enamel conditioners on the bond strength of orthodontic brackets. J Contemp Dent Pract. 2007; 8:36-43.

7. Bishara SE, Soliman M, Laffoon JF, Warren J. Shear Bond Strength of a New High Fluoride Release Glass Ionomer Adhesive. Angle Orthod. 2008; 78: 125-128.

8. Ozer M, Bayram M, Dincyurek C, and Tokalak F. Clinical bond failure rates of adhesive precoated self-ligating brackets using a self-etching primer. Angle Orthod. 2014; 84:155-60.

9. O'Brien KD, Read MJF, Sandison RJ, Roberts CT. A visible light-activated direct-bonding material: an in vivo comparative study. Am J Orthod Dentofac Orthop. 1989; 95:348-51.

10. Sfondrini MF, Fraticelli D, Castellazzi L, Scribante A, Gandini P. Clinical evaluation of bond failures and survival between mandibular canine-to-canine retainers made of flexible spiral wire and fiber-reinforced composite. J Clin Exp Dent. 2014; 6:e145-e149.

11. Norevall LI, Marcusson A, Persson M. A clinical evaluation of glass ionomer cement as an orthodontic bonding adhesive compared with an acrylic resin. Eur J Orthod. 1996; 18:373-84.

12. Millett DT, McCluskey LA, McAuley F, Creanor SL, Newell J, Love J. A comparative clinical trial of a compomer and a resin adhesive for orthodontic bonding. The Angle Orthodontist. 2000; 70:233-40.

13. Travess HD, Roberts-Harry, Sandy J. Orthodontics. Part 6: Risks in orthodontic treatment. Br Dent J. 2004; 196:71-7.

14. O'Reilly MM, Featherstone JD. Demineralization and remineralization around orthodontic appliances: an in vivo study. Am J Orthod Dentofacial Orthop. 1987; 92:33-40.

15. Boyd RL. Comparison of three self-applied topical fluoride preparations for control of decalcification. The Angle Orthodontist. 1993; 63:25-30.
16. Geiger A, Gorelick L, Gwinnett A, Benson B. Reducing white spot lesions in orthodontic population with fluoride rinsing. Am J Orthod Dentofacial Orthop. 1992; 101: 403-7.

17. Regalla RR, Jadav C, Babu DA, Sriram RR, Sriram SK, Kattimani VS. Evaluation and comparison of quantity and pattern of fluoride release from orthodontic adhesives: an in vitro study. J Contemp Dent Pract. 2014; 15:99-102.

18. Wiltshire WA. In vitro and in vivo fluoride release from orthodontic elastomeric ligature ties. Am J Orthod Dentofacial Orthop. 1999; 115:288-92.

19. Gillgrass TJ, Creanor SL, Foye RH, Millett DT. Varnish or polymeric coating for the prevention of demineralization? An ex vivo study. J Orthod. 2001; 28:291-5.

20. Abdelnaby YL, Al-Wakeel EE. Influence of modifying the resin coat application protocol on bond strength and microleakage of metal orthodontic brackets. Angle Orthod. 2010; 80:378-84.

21. Demito CF, Rodrigues GV, Ramos AL, Bowman SJ. Efficacy of a fluoride varnish in preventing white-spot lesions as measured with laser fluorescence. J Clin Orthod. 2011; 45:25-9.

1. Hamdan WA, Badr S, El Sayed A. The effect of fluoride varnish in preventing enamel demineralization around and under orthodontic brackets. International Ortho.2018; 16:1-11.

22. Pretty IA. Caries detection and diagnosis novel technology. J Dent. 2006; 34:277-39.

23. Lussi A, Hibst R, Paulus R. Diagnodent an optical method for caries detection. J Dent Res.2004:83 Suppl 1:C80-83.

24. Nalbantgil D, Oztoprak MO, Cakan DG, Bozkurt K, Arun T. Prevention of demineralization around orthodontic brackets using two different fluoride varnishes. European journal of dentistry. 2013; 7:41.

25. Mehta A, Paramshviam G, Chung VK, Singh S, Halaki S, Kumar S. Effect of light-curable fluoride varnish on enamel demineralization adjacent to orthodontic brackets: an in-vivo study. Am J Orthod Dentofac Orthop. 2015; 148:814-20.

26. Rock WP. Clinical performance of orthodontic brackets and adhesive systems: a randomized clinical trial. British journal of orthodontics. 1998; 25:283-7. 
27. Oz AA, Oz AZ, Arici S. In-vitro bond strengths and clinical failure rates of metal brackets bonded with different light-emitting diode units and curing times. Am J Orthod Dentofacial Orthop. 2016; 149:212-6.

28. Trimpeneers L M, Dermaut L R. A clinical trial comparing the failure rates of two orthodontic bonding systems. Am J Orthod Dentofacial Orthop. 1996; 110: 547-50.

29. Mizrahi E. Success and failure of banding and bonding. A clinical study. Angle Orthod.1982; 52: 113-7.
30. Gorelick L, Geiger AM, Gwinnett AJ. Implications of the failure rates of bonded brackets and eyelets: a clinical study. American journal of orthodontics. 1984; 1; 86:403-6.

31. Yoon TH, Lee YK, Lim BS, Kim CW. Degree of polymerization of resin composites by different light sources. J Oral Rehabil .2002; 29:1165-73.

32. Millett DT, McCluskey LA, McAuley F, Creanor SL, Nowell J, Love J. A comparative clinical trial of a compomer and a resin adhesive for orthodontic bonding. Angle Orhod.2000; 70:233-40. 